\title{
Bioavailability of isoflavone phytoestrogens in postmenopausal women consuming soya milk fermented with probiotic bifidobacteria
}

\author{
Dimitri Tsangalis ${ }^{1}$, Gisela Wilcox ${ }^{2}$, Nagendra P. Shah ${ }^{3}$ and Lily Stojanovska ${ }^{4}$ \\ ${ }^{1}$ Food Safety Authenticity and Quality Unit, Victoria University, Werribee Campus, Victoria, Australia \\ ${ }^{2}$ Clinical Nutrition and Metabolism Unit \& Monash University, Department of Medicine, Monash Medical Centre, Clayton, Victoria, \\ Australia \\ ${ }^{3}$ School of Molecular Sciences, Victoria University, Werribee Campus, Victoria, Australia \\ ${ }^{4}$ School of Biomedical Sciences, Victoria University, St Albans Campus, Victoria, Australia
}

(Received 1 April 2004 - Revised 8 July 2004 - Accepted 9 September 2004)

\begin{abstract}
We investigated the effects of consuming an isoflavone aglycone-enriched soya milk containing viable bifidobacteria on urinary isoflavone excretion and percentage recovery. Sixteen postmenopausal women were randomly divided into two groups to consume either fermented or non-fermented soya milk. Each group participated in a double-blind, crossover study with three $14 \mathrm{~d}$ supplementation periods, separated by a $14 \mathrm{~d}$ washout. Subjects ingested three daily dosages of isoflavone via the soya milk and collected four $24 \mathrm{~h}$ pooled urine specimens per supplementation period. Soya milks were prepared with soya protein isolate and soya germ, followed by fermentation with bifidobacteria. Isoflavone levels were quantified using HPLC. Non-fermented soya milks at 20, 40 and $80 \mathrm{mg}$ isoflavone $/ 200 \mathrm{ml}$ contained $10 \%, 9 \%$ and $7 \%$ aglycone, respectively, with their fermented counterparts containing $69 \%, 57 \%$ and $36 \%$ aglycone $(P<0 \cdot 001)$. A trend to a greater percentage urinary recovery of daidzein and glycitein was observed among women consuming fermented soya milk at a dosage of $40 \mathrm{mg}$ isoflavone $(P=0.13)$. A distinct linear dose response for the fermented soya milk group $\left(R^{2}=0.9993\right)$ compared with the non-fermented group $\left(R^{2}=0.8865\right)$ suggested less interindividual variation in isoflavone absorption. However, total urinary isoflavone excretion was similar for both groups $(P>0.05)$, with urinary isoflavone recovery at approximately $31 \%$. Increasing the isoflavone dosage correlated positively with its urinary excretion, but urinary percentage recovery of isoflavone was inversely related to dosage level. Hence, a modest dosage ranging from 20 to $30 \mathrm{mg} / \mathrm{d}$ may provide the most bioavailable source of isoflavone, regardless of whether it is via an aglycone-rich fermented soya milk or a glucoside-rich soya milk.
\end{abstract}

Isoflavone: Bifidobacteria: Soya milk: Bioavailability: Postmenopausal women

Diminishing levels of oestrogen caused by ovarian failure, inadequate to maintain oestrogen-dependent tissues, are associated with higher rates of chronic disease in postmenopausal women. Phytoestrogens, a group of non-steroidal plant-derived compounds, are structurally similar to oestrogen and thus able to exert weak oestrogenic effects (Mayr et al. 1992; Markiewicz et al. 1993). Specifically, isoflavone phytoestrogens found abundantly in soyabeans are bioactive di-phenolic structures able to bind to oestrogen receptor sites (Setchell \& Cassidy, 1999). Isoflavones behave in a similar manner to selective oestrogen-receptor modulators, acting as oestrogen agonists and antagonists in different tissues (Brzezinski \& Debi, 1999). Hence, isoflavones have been associated with the prevention of hormone-dependent disorders based on epidemiological (Lee et al. 1991; Setchell, 1995; Cassidy, 1996) and small-scale human clinical studies (Anderson et al. 1995; Kurzer, 2000).

Soyabeans contain three types of isoflavone, each type being present in four chemical forms. Aglycone structures of daidzein, genistein and glycitein are those forms with an oestrogen-like configuration and functionality but are found in soyabean foods predominantly as malonyl-, acetyl- and $\beta$-glucoside conjugates (>90\% of the total concentration; Murphy et al. 1999). Izumi et al. (2000) found that isoflavone aglycones were absorbed more quickly and in greater amounts than their glucosides in human subjects. Furthermore, Setchell et al. (2002) reported that isoflavone glucosides were not absorbed intact across the enterocytes of adults, their bioavailability requiring hydrolysis of the sugar moiety by intestinal $\beta$-glucosidases. This suggests that consuming isoflavone aglycone-rich soya foods may be more effective than consuming glucoside-rich products in preventing chronic disease. However, Richelle et al. (2002) discovered that the enzymic hydrolysis of isoflavone glucosides into aglycones in a soya drink (made from soya germ (SG)) before consumption did not enhance the absorption of isoflavones in postmenopausal women after a single dose; plasma and urine isoflavone pharmacokinetics were similar for both aglycone- and glucoside-rich soya drinks. In contrast, Hutchins et al. (1995) and Slavin et al. (1998) reported that the fermentation of cooked soyabeans by Rhizopus oligosporus (tempeh) enhanced the bioavailability of daidzein and genistein in men and women over a $9 \mathrm{~d}$ feeding period (112 $\mathrm{g}$ tempeh/d) compared with the ingestion of non-fermented cooked soyabean pieces under identical conditions.

\footnotetext{
Abbreviations: AUC, area under the curve; CFU, colony-forming units; FS, fermented soya milk ; ISTD, internal standards; NFS, non-fermented soya milk; SG, soya germ; SPI, soya protein isolate; UV/VIS, UV/visible.

* Corresponding author: Dr Gisela Wilcox, fax +61 39594 6370, email gwilcox@bigpond.net.au
} 
Intestinal bacteria play an important role in the ultimate bioactivities of isoflavones (Hendrich, 2002; Turner et al. 2003). Isoflavones are excreted in urine and found predominantly as glucuronide and sulphate conjugates. Owing to their phenolic nature, isoflavones undergo biotransformation at hydroxyl groups by mammalian UDP-glucuronosyltransferases and sulphotransferases in the intestinal mucosa and liver (Hendrich, 2002). To date, studies on the pharmacokinetics of isoflavones in human subjects have not investigated the effects of fermenting soya foods with bifidobacteria. Bifidobacteria constitute a major part of the natural microflora of the human intestine, their highest populations being found in the ileum and colon (Orrhage \& Nord, 2000). We discovered that $\beta$-glucosidase-producing Bifidobacterium animalis $\mathrm{Bb}-12$ hydrolysed isoflavone glucosides into bioactive and bioavailable aglycones when grown in soya milk (Tsangalis et al. 2002, 2003, 2004). In clinical studies, B. animalis Bb-12 has also been shown to effectively modulate intestinal microbial balance (Playne, 2002). Hence, the enrichment of isoflavone aglycone in soya milk by fermentation prior to consumption and the modulation of intestinal microflora via the ingestion of viable bifidobacteria may enhance the bioavailability of isoflavones consumed on a daily basis.

The objective of this study was to investigate the effects of the daily consumption of an isoflavone aglycone-enriched fermented soya milk containing viable populations of $B$. animalis Bb-12 on urinary isoflavone excretion and percentage recovery in postmenopausal women.

\section{Subjects and methods}

\section{Subjects}

Sixteen healthy postmenopausal women were recruited from the Melbourne metropolitan area from fifty-two interested volunteers. They were screened using a health-information and food-frequency questionnaire designed to exclude those who: had gastrointestinal disorders; had food allergies; had an alcohol intake greater than two standard drinks per day; regularly used prescription or non-prescription medication; had been on oestrogen-replacement therapy or antibiotics in the past 3 months; or had dietary patterns that were not representative of the general population (e.g. strict vegetarian, consumption of more than two servings of soya food per week). Participants were randomly allocated to one of two groups (eight subjects per group), to consume either fermented or non-fermented soya milk during the supplementation periods. The mean age of women in the fermented soya milk (FS) and non-fermented soya milk (NFS) group was 52.5 (SD 3.1) and 55.6 (SD 5.1) years, respectively. Five women in the FS group and six women in the NFS group had not had any menstrual bleeding for at least 12 months; the other women recruited had not menstruated for at least 6 months.

\section{Study design}

The study protocol was approved by the Human Research Ethics Committee of Victoria University (Melbourne, Victoria, Australia) and consisted of a randomised, double-blind, crossover design involving three $14 \mathrm{~d}$ soya milk supplementation periods separated by two $14 \mathrm{~d}$ washout periods. Subjects consumed either fermented or non-fermented soya milk containing three different concentrations of total isoflavone during each respective $14 \mathrm{~d}$ supplementation period. All batches of fermented soya milk contained a consistent population of $B$. animalis $\mathrm{Bb}-12$, at $10^{8}$ viable cells $/ \mathrm{ml}$. A volume of $200 \mathrm{ml}$ chilled $\left(4^{\circ} \mathrm{C}\right)$ fermented soya milk was required per day, $100 \mathrm{ml}$ before breakfast and before dinner. Each participant consumed a self-selected diet for the entire study and provided a $14 \mathrm{~d}$ weighed food and beverage record during each supplementation period. Subjects were advised not to alter their diet for the duration of the study and were asked to exclude foods containing soya as an ingredient, chickpeas, lentils, beans (all types), alfalfa, mung bean sprouts, fermented dairy products, probiotic supplements and alcoholic beverages. Daily energy, macronutrient and dietary fibre intake were quantified for each subject using Food Works version 3.01 nutrition software utilising a database of Australian foods (Xyris Software Pty Ltd, Highgate Hill, Queensland, Australia). Anthropometric measurements of height $(\mathrm{m})$ and body weight $(\mathrm{kg})$ were recorded and the BMI of each subject calculated $\left(\mathrm{kg} / \mathrm{m}^{2}\right)$ before and after each supplementation period.

\section{Collection and handling of urine specimens}

Each participant collected four $24 \mathrm{~h}$ pooled urine specimens per soya milk supplementation period: a day before beginning soya milk supplementation (baseline) and on days 4, 13 and 14 . Twenty-four hour pooled urine specimens consisted of the second urination on the allocated day and those following, and included the first urination on the next day, and were passed into 3.2 litre sterile plastic bottles (Biocorp Pty Ltd, Huntingdale, Victoria, Australia) containing $2 \mathrm{~g}$ ascorbic acid (Sigma Chemical Co., Castle Hill, New South Wales, Australia) as preservative against chemical degradation. Specimens were stored at $4^{\circ} \mathrm{C}$ or on ice until processed. The total volume of each $24 \mathrm{~h}$ pooled urine specimen was measured and a $100 \mathrm{ml}$ aliquot taken for urinary isoflavone analyses. Prior to storage at $-20^{\circ} \mathrm{C}, 1 \mathrm{ml} 10 \%(\mathrm{w} /$ v) sodium azide (Labchem Pty Ltd, Auburn, Australia) was added to the aliquot as a preservative against microbial spoilage.

\section{Soya milk ingredients}

Bifidobacterium animalis $\mathrm{Bb}-12$ was obtained from Chr Hansen Pty Ltd (Bayswater, Australia) and stored at $-80^{\circ} \mathrm{C}$ in $12 \%(w /$ v) sterile $\left(121^{\circ} \mathrm{C}\right.$ for $\left.15 \mathrm{~min}\right)$ reconstituted skim milk supplemented with D-glucose $(1 \% \mathrm{w} / \mathrm{v})$, yeast extract $(0.5 \% \mathrm{w} / \mathrm{v})$ and glycerol $(40 \% \mathrm{v} / \mathrm{v})$. Supro 159 soya protein isolate (SPI) was obtained from Protein Technologies International Australia (Kensington, Australia); this, according to manufacturer specifications, contained a minimum of $90 \mathrm{~g}$ protein, $4 \mathrm{~g}$ fat and $4 \mathrm{~g}$ or less soluble carbohydrates per $100 \mathrm{~g}$. IsoLife SG was obtained from Soy Health Pty Ltd (Sydney, Australia) and comprised a macronutrient composition of $40 \mathrm{~g}$ protein, $16 \mathrm{~g}$ fat and $25 \mathrm{~g}$ carbohydrate per $100 \mathrm{~g}$. The total concentration of isoflavone in this brand of SPI and SG was 1.4 and $19.4 \mathrm{mg} / \mathrm{g}$, respectively (Tsangalis et al. 2004). Vanilla flavour (in propylene glycol) was purchased from Essential Flavours and Ingredients (Rowville, Australia).

\section{Manufacture of soya milk}

Three soya milk formulations were manufactured, each containing a different ratio of SPI to SG (total of $4 \% \mathrm{w} / \mathrm{v}$ soya ingredients), the calculation being based upon the concentration of isoflavone in each soya ingredient. SPI and SG at ratios of 9.4:0.6, 
$8 \cdot 0: 2 \cdot 0$ and $5 \cdot 2: 4 \cdot 8$ were used to manufacture soya milks containing approximately 20 (SPI/SG20), 40 (SPI/SG40) and 80 (SPI/SG80) $\mathrm{mg}$ isoflavone per $200 \mathrm{ml}$, respectively. For SPI/ SG20, $748 \mathrm{~g}$ SPI and $52 \mathrm{~g}$ SG were reconstituted in 20 litres filtered water at a temperature of $40^{\circ} \mathrm{C}$, followed by heating with stirring at $70^{\circ} \mathrm{C}$ for 30 min during which $80 \mathrm{ml}$ vanilla flavour was added. The soya milk was then dispensed into four bottles in 5 litre quantities and autoclaved at $121^{\circ} \mathrm{C}$ for $15 \mathrm{~min}$. Two bottles of sterile soya milk (10 litres) were cooled to approximately $75 \pm 5^{\circ} \mathrm{C}$, and $200 \mathrm{ml}$ non-fermented product was dispensed into forty-five sterile, $200 \mathrm{ml}$ high-density polyethylene bottles (Cospak Pty Ltd, Braeside, Australia) under aseptic conditions using a $100 \mathrm{ml}$ Trubor bottle top dispenser (U-Lab Pty Ltd, Eltham, Australia). Aliquots of $100 \mathrm{ml}$ from three randomly selected bottles of non-fermented soya milk were obtained under aseptic conditions and freeze-dried $(50 \mathrm{ml}$ aliquot) using a Dynavac FD300 freeze-drier (Rowville, Australia) for extraction of isoflavone and analysis using HPLC. Fourteen bottles of non-fermented soya milk were packaged and stored at $4{ }^{\circ} \mathrm{C}$ prior to distribution. The remaining 10 litres of sterile soya milk were cooled to $40^{\circ} \mathrm{C}$ prior to inoculation with an active culture of B. animalis $\mathrm{Bb}-12$. SPI/SG40 and SPI/SG80 were also manufactured in the same manner using SPI-SG $638 \mathrm{~g}: 162 \mathrm{~g}$ and SPI-SG $416 \mathrm{~g}: 384 \mathrm{~g}$, respectively, per 20 litres of filtered water.

\section{Bacterial growth media}

Rehydrated MRS agar (De Mann et al. 1960) containing additional $1 \%(\mathrm{w} / \mathrm{v}) \mathrm{D}$-glucose was prepared as per manufacturer instructions (Oxoid Ltd, West Heidelberg, Victoria, Australia) and autoclaved at $121^{\circ} \mathrm{C}$ for $15 \mathrm{~min}$. Filter-sterilised L-cysteine$\mathrm{HCl}$ solution $(5 \% \mathrm{w} / \mathrm{v})$ was added to the agar $(0.05 \% \mathrm{w} / \mathrm{v}$ final concentration) just prior to inoculation with bacteria to lower the oxidation-reduction potential of the media and enhance the growth of anaerobic bifidobacteria. D-Glucose and L-cysteine$\mathrm{HCl}$ were purchased from Sigma.

Reconstituted SPI at a ratio of $24 \mathrm{~g} / 600 \mathrm{ml}$ filtered water supplemented with $1 \%(\mathrm{w} / \mathrm{v})$ food-grade glucose powder (Prahran Health Foods, Prahran, Australia) was prepared for the activation of B. animalis $\mathrm{Bb}-12$, as described earlier (Tsangalis et al. 2004). A $600 \mathrm{ml}$ batch was manufactured and dispensed into glass bottles in 20,50 and $500 \mathrm{ml}$ quantities and sterilised by autoclaving at $121^{\circ} \mathrm{C}$ for $15 \mathrm{~min}$.

\section{Fermentation of soya milk with bifidobacteria}

Bifidobacterium animalis $\mathrm{Bb}-12$ was activated by three successive transfers. An inoculum level of $5 \%(\mathrm{v} / \mathrm{v})$ was used for strain activation, and incubation was at $37^{\circ} \mathrm{C}$ for $20 \mathrm{~h}$. Sterile soya milk (SPI/SG20, SPI/SG40 and SPI/SG80 10 litres) was inoculated with an active culture of $B$. animalis Bb-12 (5\% v/v). A volume of $200 \mathrm{ml}$ inoculated soya milk was dispensed into forty-eight sterile $200 \mathrm{ml}$ high-density polyethylene bottles under aseptic conditions using a $100 \mathrm{ml}$ Trubor bottle-top dispenser and incubated at $37^{\circ} \mathrm{C}$ for $24 \mathrm{~h}$. Three bottles were randomly taken from the batch at 0 and $24 \mathrm{~h}$ of incubation, and a $100 \mathrm{ml}$ sample was withdrawn aseptically from each bottle for the enumeration of viable $B$. animalis $\mathrm{Bb}-12$ populations (as described by Tsangalis et al. 2004), the remainder being stored at $-20^{\circ} \mathrm{C}$. Frozen samples were freeze-dried $(50 \mathrm{ml}$ aliquot) using a Dynavac FD300 freeze-drier for the extraction of isoflavone and analysis using HPLC. The remaining forty-two bottles of fermented soya milk were equally packaged into three cartons and stored at $4^{\circ} \mathrm{C}$ prior to distribution.

\section{Isoflavone standards}

Aglycone standards of genistein, daidzein and glycitein (synthetic) used for both soya milk and urinary isoflavone analyses were purchased from Sigma. $\beta$-Glucoside isomers of genistin, daidzin and glycitin were purchased from Indofine Chemical Co (Somerville, USA). Internal standards (ISTD) of flavone and benzophenone, used for the quantification of isoflavones in soya milk and urine, respectively, were obtained from Sigma. Mixed and single isoflavone standards used in the analysis of isoflavones in soya milk were prepared as described earlier (Tsangalis et al. 2002).

\section{Reversed-phase HPLC apparatus and reagents}

Chromatographic analyses were carried out on a Varian 9000 series high-performance liquid chromatograph (Varian Pty Ltd, Mulgrave, Australia) with auto-sampler (9100), solvent delivery system (9010), polychrom photodiode array UV/visible (UV/ VIS) detector (9065) and thermostatically controlled column compartment (Alltech Associates Pty Ltd, Box Hill, Australia). An Exsil (SGE International Pty Ltd, Ringwood, Australia) C18-ODS $(250 \times 4.6 \mathrm{~mm}$ internal diameter $5 \mu \mathrm{m})$ reversedphase column was used to separate the isoflavone isomers. HPLC-grade methanol and acetonitrile were purchased from Merck Pty Ltd (Kilsyth, Australia) and trifluoro-acetic acid, glacial acetic acid, sodium acetate and ammonium acetate from Sigma. All reagents used for soya milk and urinary isoflavone extraction and HPLC analyses were filtered through a $0.5 \mu \mathrm{m}$ membrane (Millipore, Bedford, USA), and mobile phases were degassed using nitrogen.

\section{Extraction and HPLC analysis of isoflavones in soya milk}

A sample of SPI powder $(2 \mathrm{~g}), 1.50 \mathrm{~g}$ freeze-dried SPI/SG20, $1.00 \mathrm{~g}$ freeze-dried SPI/SG40 or $0.50 \mathrm{~g}$ either freeze-dried SPI/ SG80 or SG powder was used in the extraction of isoflavone isomers (malonyl, acetyl, $\beta$-glucoside and aglycone forms), as described earlier (Tsangalis et al. 2002). HPLC gradient elution was composed of acetonitrile (solvent A) and $10 \mathrm{~mm}$-ammonium acetate buffer containing $0.1 \%$ trifluoro-acetic acid (solvent B), set at a flow rate of $1 \mathrm{ml} / \mathrm{min}$ (Setchell et al. 2001). After a $20 \mu \mathrm{L}$ injection of sample or isoflavone standard on to the column $\left(25^{\circ} \mathrm{C}\right)$, solvent $\mathrm{B}$ was set at $100 \%$ for $2 \mathrm{~min}$, reduced to $40 \%$ over $22 \mathrm{~min}$ followed by $40 \%$ for $5 \mathrm{~min}$, increased to $100 \%$ over $6 \mathrm{~min}$ and finally increased to $100 \%$ for $5 \mathrm{~min}$ prior to the next injection. The diode array UV/VIS detector was set at $259 \mathrm{~nm}$, and the retention times (min) of isoflavone isomers were as follows: malonyldaidzin, 13.7; malonylglycitin, 14.0; malonylgenistin, 14.3; daidzin, 14.6; glycitin, 14.8; genistin, 16.2; acetyldaidzin, 16.9; acetylglycitin, 17.1; acetylgenistin, 18.7; daidzein, 19.2; glycitein, 19.5; genistein, 21.7; and flavone (ISTD), 28.2. Retention times for aglycone and $\beta$-glucoside isoflavone isomers were determined using single standards, whereas those of malonyl- and acetyl-glucoside isomers were based on the retention times reported by Setchell et al. (2001) under similar HPLC conditions. Quantification of isoflavone isomers in soya 
milk using multi-level calibration and an ISTD was as described by Tsangalis et al. (2002). Isoflavone concentrations are expressed as $\mu \mathrm{mol} / 200 \mathrm{ml}$ soya milk (calculated back to wet basis).

\section{Analysis of isoflavones in urine specimens}

Aliquots from $24 \mathrm{~h}$ pooled urine specimens were analysed for their daidzein, genistein and glycitein concentration. Urine samples were extracted for isoflavone and analysed in batches over consecutive days with all the specimens from one subject run in the same batch. Extraction of urinary isoflavones was performed described by Franke \& Custer (1994), with modifications as follows. Frozen urine aliquots were equilibrated to room temperature, vortex-mixed and centrifuged (Sorvall RT7 refrigerated centrifuge; Newtown, USA) at $2700 \mathrm{~g}$ for $10 \mathrm{~min}$. A volume of $20 \cdot 2 \mathrm{ml}$ clear supernatant was mixed with $5.0 \mathrm{ml} 0.2 \mathrm{M}$ acetate buffer ( $\mathrm{pH} 4)$ and $120 \mu \mathrm{l}$ benzophenone $(10 \mathrm{mg} / 50 \mathrm{ml}$ methanol) and filtered through a C18 solid-phase extraction column (Alltech) preconditioned with $5.0 \mathrm{ml}$ methanol and $5.0 \mathrm{ml} 0.2 \mathrm{M}$-acetate buffer $(\mathrm{pH} 4)$. After passing the entire urine sample through the column, the column was washed with $2.0 \mathrm{ml} 0.2$ M-acetate buffer ( $\mathrm{pH} 4)$, and the isoflavones were eluted with $100 \%$ methanol to give exactly $2.0 \mathrm{ml}$. A volume of $100 \mu \mathrm{l}$ of this eluate was used for the analysis of unconjugated forms of daidzein, genistein and glycitein. The residual $1.9 \mathrm{ml}$ of eluate was dried under a stream of nitrogen using a Pierce nine-needle evaporating unit (Pierce Biotechnology Inc., Rockford, USA) and then resuspended in $900 \mu \mathrm{l}$ freshly prepared mixture comprising $10 \mathrm{ml} 0 \cdot 2$ $\mathrm{M}$-acetate buffer ( $\mathrm{pH} 4), 150 \mathrm{mg}$ ascorbic acid and $500 \mu \mathrm{L}$ glucuronidase/sulphatase (sterile filtered crude solution isolated from Helix pomatia type HP-2S; Sigma). The hydrolysed sample (total of unconjugated and conjugated isoflavones) was then mixed with $1.0 \mathrm{ml} 100 \%$ methanol, centrifuged at $4000 \mathrm{~g}$ for $5 \mathrm{~min}$, and $50 \mu \mathrm{l}$ were injected on to the column $\left(25^{\circ} \mathrm{C}\right)$. HPLC conditions were as described by Xu et al. (1994), with the diode array UV/VIS detector set at $259 \mathrm{~nm}$ to detect daidzein, genistein and glycitein. Six mixed standards containing daidzein, genistein and glycitein $(50,100,150,250,350$ and $450 \mathrm{ng} / 50 \mu \mathrm{l})$ were used for the quantification of isoflavones. Benzophenone (ISTD) was added to each isoflavone standard at a concentration of $600 \mathrm{ng} / 50 \mu \mathrm{l}$. Single standards were also prepared for peak identification, and the retention times ( $\mathrm{min}$ ) of isoflavone isomers were as follows: daidzein, 15.5; glycitein, 16.8; genistein, 19.8; and benzophenone (ISTD), 28.8. Isoflavone concentrations were calculated with respect to the ISTD and multiplied to represent the entire pooled urine specimen.

\section{Statistical analysis}

Non-fermented and fermented SPI/SG20, SPI/SG40 and SPI/ SG80 were manufactured on three occasions, with three bottles of soya milk randomly selected from each batch and their isoflavone content and viable $B$. animalis $\mathrm{Bb}-12$ populations analysed in duplicate. Hence, populations of B. animalis Bb-12 in fermented soya milks consumed during each supplementation period are reported as a mean with standard deviation of six replicates, and the concentrations of each isoflavone isomer in non-fermented and fermented soya milks consumed during the entire study are presented as a mean with standard deviation of eighteen replicates. For the FS and NFS groups, concentrations of daidzein, genistein and glycitein in $24 \mathrm{~h}$ pooled urine specimens were analysed in duplicate and are presented as a mean with standard deviation of sixteen replicates. To find significant differences in body weight, BMI, nutrient intake, viability of B. animalis $\mathrm{Bb}-12$ and isoflavone levels in soya milk, and urinary isoflavone excretion, means were analysed using ANOVA and $95 \%$ CI with Microsoft Excel Stat Pro, as described by Albright et al. (1999). ANOVA data with a $P<0.05$ were classified as statistically significant (two-sided test).

\section{Results and discussion}

\section{BMI and body weight}

The mean with standard deviation BMI [body weight] of the NFS and FS groups $(n 8)$ at baseline (i.e. a day before the first supplementation period) were $29.3(\mathrm{SD} 6.2) \mathrm{kg} / \mathrm{m}^{2}$ [71.3 (SD 13.4) $\mathrm{kg}$ ] and $24.6(\mathrm{SD} 5.4) \mathrm{kg} / \mathrm{m}^{2}$ [61.9 (SD 11.3) $\mathrm{kg}$ ], respectively, with no significant difference in either BMI $(P=0 \cdot 13)$ or body weight $(P=0.15)$ between the two groups. No significant fluctuations in body weight were observed during the entire span of supplementation and washout periods for the NFS and FS groups $(P>0.05)$. Hence, the mean BMI of the NFS and FS groups after the final supplementation period were 28.9 (SD 5.6) and 24.3 (SD 5.3 ) $\mathrm{kg} / \mathrm{m}^{2}$, respectively, similar to their respective baseline values $(P>0 \cdot 05)$.

\section{Intake of dietary nutrients, viable bifidobacteria and isoflavones}

The mean daily energy intake for women in the FS and NFS groups ranged between 5698.8 (SD 1478.9) and 6445.9 (SD 1568.6) $\mathrm{kJ} / \mathrm{d}$, with no significant differences in daily energy intake between the two groups during the supplementation periods $(P=0 \cdot 9)$. The mean daily intake of macronutrients for the FS and NFS groups during supplementation are shown in Fig. 1. Both groups of women consumed an average of $20 \%$ energy in the form of protein, $44 \%$ energy as carbohydrates and $36 \%$ as fat (total intake of polyunsaturated, monounsaturated and saturated fats) per day during supplementation. There were no significant differences in protein $(P=0 \cdot 8)$, carbohydrate $(P=0 \cdot 7)$, fat $(P=0.9)$ and dietary fibre $(P=0.9)$ intake $(\mathrm{g} / \mathrm{d})$ between the FS and NFS groups during supplementation periods.

According to the protein content of SPI and SG, non-fermented SPI/SG20, SPI/SG40 and SPI/SG80 comprised 6.96, 6.40 and $5.28 \mathrm{~g}$ protein per $200 \mathrm{ml}$ serving, respectively. The concentration of carbohydrate (and fibre) in non-fermented SPI/SG20, SPI/ SG40 and SPI/SG80 was $0.42 \mathrm{~g}(0.01 \mathrm{~g}), 0.66 \mathrm{~g}(0.05 \mathrm{~g})$ and $1.13 \mathrm{~g}(0 \cdot 12 \mathrm{~g})$ per $200 \mathrm{ml}$ serving, respectively. The total concentration of polyunsaturated, monounsaturated and saturated fats in non-fermented SPI/SG20, SPI/SG40 and SPI/SG80 was 0.38, 0.51 and $0.78 \mathrm{~g}$ per $200 \mathrm{ml}$ serving, respectively. Each of the soya milks contributed relatively little to the mean intake of macronutrients ingested per day by women in the FS and NFS groups, being approximately $8.5 \%, 0.4 \%, 1.0 \%$ and $0.3 \%$ of the daily intake of protein, carbohydrate, fat and fibre, respectively. Fermented SPI/SG20, SPI/SG40 and SPI/SG80 may have contained a lower level of protein, carbohydrate, fat and fibre than their non-fermented counterparts, as each of these nutrients could have been metabolised as a growth substrate during the fermentation of bifidobacteria (Kamaly, 1997; Hou et al. 2000).

Viable populations of B. animalis Bb-12 in fermented SPI/ SG20, SPI/SG40 and SPI/SG80 (200 ml serving) consumed by 
women in the FS group during supplementation ranged from 7.60 (SD 0.06) to 8.87 (SD 0.08) $\log _{10}$ colony-forming units (CFU) per $\mathrm{ml}$. This level of viable bifidobacteria exceeded the minimum level considered to be of therapeutic dosage, at $6 \log _{10} \mathrm{CFU} / \mathrm{ml}$ (Gomes \& Malcata, 1999). Such high numbers of bifidobacteria compensate for the possible reduction in number of viable cells during passage through the stomach and intestine. There were no significant differences between $B$. animalis $\mathrm{Bb}-12$ populations found in fermented SPI/SG20, SPI/SG40 and SPI/SG80 $(P=0.07)$. Furthermore, similar populations of $B$. animalis $\mathrm{Bb}-$ 12 were ingested during each supplementation period $(P=0 \cdot 08)$.

Mean concentrations of isoflavone isomers in non-fermented and fermented SPI/SG20, SPI/SG40 and SPI/SG80 ingested per day (via a $200 \mathrm{ml}$ serving) during soya milk supplementation are shown in Table 1; each value is expressed as $\mu \mathrm{mol}$ so that it can be compared with the levels of isoflavone $(\mu \mathrm{mol} / \mathrm{d}$ ) excreted in urine. Non-fermented SPI/SG20, SPI/SG40 and SPI/ SG80, which were formulated to contain 20,40 and $80 \mathrm{mg}$ isoflavone $/ 200 \mathrm{ml}$, were equivalent to $64.11,101.80$ and $172.28 \mu \mathrm{mol}$ aglycone constituents per $200 \mathrm{ml}$, respectively. The highest daily dose of isoflavone via SPI/SG80 was about 1.7 and 2.6 times the isoflavone concentration of SPI/SG40 and SPI/SG20, respectively $(P<0 \cdot 001)$. Non-fermented SPI/SG20, SPI/SG40 and SPI/SG80 comprised $10 \%, 9 \%$ and $7 \%$ of its isoflavone level as unconjugated aglycone, respectively. Fermentation of SPI/SG20, SPI/SG40 and SPI/SG80 with B. animalis Bb-12 significantly increased the proportion of aglycone structures to $69 \%, 57 \%$ and $36 \%$ of total isoflavone, respectively $(P<0 \cdot 001)$. Fermented SPI/SG40 and SPI/SG80 contained the highest concentration of aglycone structures at 57.74 and $61.67 \mu \mathrm{mol} / 200 \mathrm{ml}$, significantly higher than the other soya milks $(P<0 \cdot 001)$. However, changes in isoflavone isomer composition were less apparent in SPI/SG80 after fermentation. In an earlier study (Tsangalis et al. 2004), we reported that the $\beta$-glucosidase levels produced by $B$. animalis $\mathrm{Bb}-12$ during fermentation were insufficient to hydrolyse high levels of isoflavone glucoside in the range found in SPI/SG80. Furthermore, SPI/SG80 comprised the greatest concentration of glycitin, malonylglycitin and acetylglycitin (approximately 35\% of total isoflavone), which we found to be poorly hydrolysed by $\beta$-glucosidase during soya milk fermentation with $B$. animalis $\mathrm{Bb}-12$ (Tsangalis

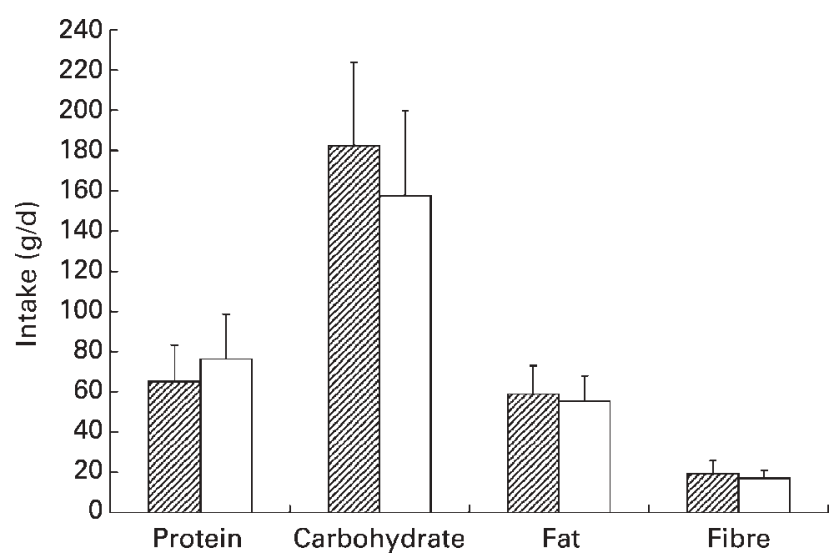

Fig. 1. Daily intake of macronutrients for the fermented soya milk (FS and non-fermented soya milk (NFS $\square$ ) group during supplementation. Fat intake represents the total of polyunsaturated, monounsaturated and saturated fats. Columns and errors bars represents mean and standard deviations of twenty-four replicates (eight subjects and three supplementation periods). et al. 2004). The high concentration of glycitein and its glucosides in SPI/SG80 was a result of the greater proportion of SG powder in the soya milk formulation. SG is a concentrated source of isoflavone naturally found in the soyabean's hypocotyl, the only part of the bean that contains glycitein and its glucosides at a concentration higher than both daidzein and genistein and their glucosides (Kudou et al. 1991).

\section{Urinary isoflavone excretion after consumption of fermented and non-fermented soya milk}

Interindividual variation in intestinal microflora has been shown to affect the bioavailability of isoflavones (Hendrich, 2002). The influence of diet on the bioavailability of isoflavones has also been observed (Setchell et al. 1984; Kelly et al. 1993; Lampe et al. 1998). The ingestion of viable bifidobacteria to modulate intestinal microflora and its possible effect on the bioavailability of isoflavones has not been studied. Changes in intestinal microflora occur from birth to old age; with young adult women having a different intestinal microbial ecology from those women in their postmenopausal years (Ballongue, 1993). Mitsuoka (1984) reported that the number of Bifidobacterium in adult stools, particularly those of the elderly, was significantly lower than the populations of Bifidobacterium found in the stool samples of children. Therefore, owing to the relevance of isoflavone-rich soyabean foods to postmenopausal women and considering the variation in intestinal microflora over different stages of life, we limited the inclusion of subjects to women between the ages of 45 and 65 years. Furthermore, we segregated those women consuming fermented soya milk from those consuming the non-fermented product, as we expected changes in intestinal microbial composition in the group of women consuming bifidobacteria.

Mean concentrations of isoflavone excreted in urine by the FS and NFS groups at 4,13 and 14 days of soya milk supplementation are shown in Table 2, with the concentrations representing the sum of unconjugated forms of daidzein, genistein and glycitein and their deconjugated glucuronide and sulphate isomers. The proportion of unconjugated isoflavone metabolites excreted in urine by the FS and NFS groups ranged between $0.6 \%$ and $3.0 \%$ of total urinary isoflavone. Similarly, Zhang et al. (2003) found that the percentage of aglycone forms excreted in urine by young adult women after the ingestion of non-fermented soya milk was $4-5 \%$ of total isomers, with daidzein and genistein glucuronides representing $73 \%$ and $71 \%$ of total daidzein and genistein excreted in urine, respectively. As shown in Table 2 , women from both the FS and NFS groups excreted the greatest level of isoflavone $(38-53 \mu \mathrm{mol} / \mathrm{d})$ during supplementation with SPI/SG80, which contained the highest dose of isoflavone (Table 1). The level of isoflavone excreted in urine during supplementation with SPI/SG80 was significantly greater than the levels excreted during supplementation with SPI/SG20 and SPI/ SG40 for both the FS and NFS groups on day $4(P<0 \cdot 001), 13$ $(P<0.001)$ and $14(P<0.001)$ (Table 2). Hence, a higher ingested dose of isoflavone via SPI/SG80 appeared to enhance the amount of isoflavone absorbed and subsequently excreted during soya milk supplementation. Likewise, Xu et al. (1994) reported that total urinary isoflavones increased significantly with increasing dose $(P<0.05)$.

The ingestion of fermented soya milk did not appear to enhance the urinary excretion of isoflavone at any of the isoflavone 
Table 1. Concentration of isoflavone isomers ( $\mu \mathrm{mol} / 200 \mathrm{ml}$ serving) in non-fermented and fermented soya milks SPI/SG20, SPI/SG40 and SPI/SG80 (Mean values with their standard deviations; $n$ 18)

\begin{tabular}{|c|c|c|c|c|c|c|c|c|c|c|c|c|}
\hline \multirow{2}{*}{ Isoflavone isomer } & \multicolumn{6}{|c|}{ Non-fermented } & \multicolumn{6}{|c|}{ Fermented $^{*}$} \\
\hline & \multicolumn{2}{|c|}{ SPI/SG20 } & \multicolumn{2}{|c|}{ SPI/SG40 } & \multicolumn{2}{|c|}{ SPI/SG80 } & \multicolumn{2}{|c|}{ SPI/SG20 } & \multicolumn{2}{|c|}{ SPI/SG40 } & \multicolumn{2}{|c|}{ SPI/SG80 } \\
\hline Daidzein & $3.42^{f}$ & 0.93 & $4 \cdot 77^{\text {ef }}$ & 0.97 & $6 \cdot 24^{\mathrm{de}}$ & 0.98 & $17 \cdot 01^{\mathrm{c}}$ & 1.08 & $23 \cdot 84^{\mathrm{b}}$ & 1.96 & $29 \cdot 00^{\mathrm{a}}$ & 4.87 \\
\hline Genistein & $2 \cdot 03^{\mathrm{de}}$ & 0.63 & $2 \cdot 26^{\text {cde }}$ & 0.64 & $1 \cdot 84^{e}$ & 0.19 & $27 \cdot 16^{a}$ & 1.97 & $28.52^{\mathrm{a}}$ & $2 \cdot 13$ & $23 \cdot 62^{b}$ & $4 \cdot 10$ \\
\hline Glycitein & $0.74^{f}$ & 0.32 & $2 \cdot 06^{\mathrm{e}}$ & 0.76 & $3 \cdot 80^{\mathrm{cd}}$ & 0.64 & $3.01^{\text {de }}$ & 0.89 & $5 \cdot 38^{b}$ & 0.66 & $9 \cdot 05^{\mathrm{a}}$ & 1.56 \\
\hline Daidzin & $15 \cdot 23^{d}$ & 0.82 & $25 \cdot 82^{\mathrm{c}}$ & 1.62 & $49 \cdot 04^{a}$ & $2 \cdot 40$ & $4.53^{f}$ & 0.89 & $10 \cdot 70^{e}$ & $1 \cdot 32$ & $30 \cdot 51^{b}$ & $6 \cdot 21$ \\
\hline Genistin & $25 \cdot 31^{\mathrm{c}}$ & 1.46 & $28 \cdot 40^{\mathrm{b}}$ & 1.63 & $31 \cdot 13^{\mathrm{a}}$ & 1.98 & $5 \cdot 47^{f}$ & $1 \cdot 21$ & $7 \cdot 45^{\text {ef }}$ & 1.06 & $17 \cdot 41^{d}$ & $4 \cdot 26$ \\
\hline Glycitin & $9 \cdot 91^{\mathrm{ef}}$ & 0.82 & $23.08^{\mathrm{C}}$ & 1.39 & $50 \cdot 18^{\mathrm{a}}$ & 3.09 & $7 \cdot 04^{f}$ & $1 \cdot 11$ & $17 \cdot 24^{d}$ & $1 \cdot 71$ & $41 \cdot 23^{b}$ & 4.90 \\
\hline$\beta$-Glucosides† & $50 \cdot 45^{d}$ & 2.98 & $77 \cdot 30^{\mathrm{C}}$ & 4.50 & $130 \cdot 35^{a}$ & $7 \cdot 25$ & $17 \cdot 04^{f}$ & $3 \cdot 14$ & $35.39^{\mathrm{e}}$ & 3.89 & $89 \cdot 15^{\mathrm{b}}$ & $15 \cdot 20$ \\
\hline Malonyldaidzin & $0.80^{\mathrm{cd}}$ & 0.86 & $1.54^{\mathrm{abcd}}$ & 0.67 & $2 \cdot 18^{a}$ & 0.93 & $0.61^{d}$ & 0.82 & $1 \cdot 15^{\mathrm{bcd}}$ & 0.66 & $1.69^{a b c}$ & $1 \cdot 14$ \\
\hline Malonylgenistin & $0.83^{\text {cde }}$ & 0.36 & $1.69^{b}$ & 0.38 & $2 \cdot 84^{a}$ & 0.94 & $0.31^{e}$ & 0.33 & $0.64^{\mathrm{de}}$ & 0.30 & $2 \cdot 26^{\mathrm{ab}}$ & 0.83 \\
\hline Malonylglycitin & $0 \cdot 16^{d}$ & 0.20 & $0.44^{\text {bcd }}$ & 0.19 & $0.86^{a}$ & 0.24 & $0.60^{a b c}$ & 0.50 & $0.43^{\mathrm{cd}}$ & 0.20 & $0 \cdot 84^{\mathrm{a}}$ & 0.30 \\
\hline Malonylglucosides† & $1.79^{\mathrm{de}}$ & 1.28 & $3.67^{\mathrm{bc}}$ & 0.88 & $5 \cdot 88^{\mathrm{a}}$ & 1.84 & $1.52^{\mathrm{e}}$ & 0.99 & $2 \cdot 22^{\text {cde }}$ & 0.97 & $4 \cdot 79^{\mathrm{ab}}$ & $2 \cdot 12$ \\
\hline Acetylgenistin & $1 \cdot 70^{\mathrm{cd}}$ & 0.58 & $2 \cdot 88^{b}$ & 0.42 & $4 \cdot 77^{\mathrm{a}}$ & 0.91 & $0.40^{\text {ef }}$ & 0.64 & $0 \cdot 36^{f}$ & 0.38 & $1 \cdot 15^{\text {def }}$ & $1 \cdot 22$ \\
\hline Acetylglycitin & $1.59^{\mathrm{e}}$ & 0.44 & $3.99^{c}$ & 0.37 & $9 \cdot 10^{\mathrm{a}}$ & 0.81 & $0.84^{\dagger}$ & 0.39 & $2 \cdot 09^{\mathrm{de}}$ & 0.32 & $6 \cdot 20^{\mathrm{b}}$ & $1 \cdot 12$ \\
\hline Acetylglucosides & $5.68^{\mathrm{de}}$ & $1 \cdot 35$ & $11 \cdot 74^{\mathrm{C}}$ & $1 \cdot 16$ & $24 \cdot 17^{\mathrm{a}}$ & $2 \cdot 56$ & $2 \cdot 35^{\dagger}$ & 1.57 & $4 \cdot 50^{\text {ef }}$ & $1 \cdot 10$ & $13 \cdot 04^{b c}$ & 3.61 \\
\hline Total isoflavone $\ddagger$ & $64 \cdot 11^{\mathrm{e}}$ & 6.55 & $101 \cdot 80^{b c}$ & $7 \cdot 29$ & $172 \cdot 28^{\mathrm{a}}$ & $11 \cdot 83$ & $68.09^{\text {de }}$ & 7.55 & $99 \cdot 85^{\mathrm{C}}$ & $8 \cdot 27$ & $168 \cdot 65^{\mathrm{a}}$ & $13 \cdot 13$ \\
\hline
\end{tabular}

SPI/SG20, soya milk containing $20 \mathrm{mg}$ isoflavone/ $200 \mathrm{ml}$; SPI/SG40, soya milk containing $40 \mathrm{mg}$ isoflavone/200 ml; SPI/SG80, soya milk containing $80 \mathrm{mg}$ isoflavone/200 $\mathrm{ml}$. abcdef Means in the same row with different superscript are significantly different $(P<0.05)$.

* Inoculated with active culture of Bifidobacterium animalis Bb-12 and incubated for $24 \mathrm{~h}$ at $37^{\circ} \mathrm{C}$.

† Mean total of three respective isomers.

$\ddagger$ Mean total of malonyl-, acetyl-, $\beta$-glucoside and aglycone isomers.

dosages (SPI/SG20, SPI/SG40 or SPI/SG80), as there was no significant difference in urinary isoflavone excretion between the FS and NFS groups after 4, 13 and 14 days $(P>0.05)$ (Table 2). Even though fermented SPI/SG20, SPI/SG40 and SPI/SG80 contained a significantly greater proportion of isoflavone in an aglycone configuration than did its non-fermented counterpart, urinary isoflavone recovery was also similar for both the FS and NFS groups $(P>0 \cdot 05)$. Mean urinary isoflavone recovery during supplementation with fermented (and non-fermented) SPI/SG20, SPI/SG40 and SPI/SG80 was approximately $34 \%$ (39\%), $30 \%$ $(24 \%)$ and $28 \%(31 \%)$ of the ingested isoflavone dose, respectively. In comparison, Hendrich et al. (2001) investigated the recovery of isoflavones in urine, plasma and faecal specimens collected from two groups of women consuming either aglycone-rich or glucoside-rich SG concentrate and found that the bioavailability of isoflavone was similar after 4 and 7 days of supplementation. Furthermore, after a single serving of an isoflavone aglycone-rich SG beverage, Richelle et al. (2002) found that the plasma pharmacokinetics of isoflavones (apparent half-life of absorption $\left(\mathrm{T} 1 / 2_{\mathrm{abs}}\right)$, apparent half life of elimination(T1/2 elim), maximum concentration $\left(\mathrm{C}_{\max }\right)$ and the area under the curve (AUC) from 0 to $34 \mathrm{~h}$ ) in postmenopausal women were similar when the same women (in a crossover design) ingested a glucoside-rich SG equivalent $(P>0.05)$. In contrast, Setchell et al. (2001) reported that isoflavone glucosides actually showed greater bioavailability than aglycones in women ingesting a single dose,

Table 2. Urinary excretion of total isoflavone* ( $\mu \mathrm{mol} / \mathrm{d} \dagger$ ) by two groups of eight womenł during supplementation of fermented and non-fermented soya milks SPI/ SG20, SPI/SG40 and SPI/SG80

(Mean values with their standard deviations; $n$ 16§)

\begin{tabular}{|c|c|c|c|c|c|c|c|c|c|c|c|c|}
\hline \multirow{2}{*}{$\begin{array}{l}24 \mathrm{~h} \text { urine } \\
\text { collection }\end{array}$} & \multicolumn{6}{|c|}{ Non-fermented } & \multicolumn{6}{|c|}{ Fermented } \\
\hline & \multicolumn{2}{|c|}{ SPI/SG20 } & \multicolumn{2}{|c|}{ SPI/SG40 } & \multicolumn{2}{|c|}{ SPI/SG80 } & \multicolumn{2}{|c|}{ SPI/SG20 } & \multicolumn{2}{|c|}{ SPI/SG40 } & \multicolumn{2}{|c|}{ SPI/SG80 } \\
\hline Baseline & $0.44^{\mathrm{a}}$ & 0.58 & $0.41^{\mathrm{a}}$ & 0.33 & $0.22^{\mathrm{a}}$ & 0.28 & $0 \cdot 20^{\mathrm{a}}$ & 0.21 & $0.53^{\mathrm{a}}$ & 0.70 & $0.53^{\mathrm{a}}$ & 0.49 \\
\hline Day 4 & $24 \cdot 30^{\text {bcde, } \mathrm{A}}$ & $7 \cdot 22$ & $20 \cdot 42^{\mathrm{e}, \mathrm{A}}$ & 8.33 & $51 \cdot 01^{\mathrm{a}, \mathrm{A}}$ & 11.61 & $20 \cdot 67^{\text {de,A }}$ & $8 \cdot 11$ & $23.33^{\mathrm{cde}, \mathrm{A}}$ & 7.85 & $38 \cdot 29^{a, A}$ & $18 \cdot 14$ \\
\hline Day 13 & $23.83^{\mathrm{de}, \mathrm{A}}$ & 8.46 & $26 \cdot 08^{\text {cde,A }}$ & $9 \cdot 78$ & $45.42^{\mathrm{a}, \mathrm{A}}$ & $17 \cdot 68$ & $19 \cdot 91^{\mathrm{e}, \mathrm{A}}$ & $6 \cdot 44$ & $31.01^{\text {bcde }, \mathrm{A}}$ & 13.43 & $43 \cdot 27^{\mathrm{a}, \mathrm{A}}$ & $15 \cdot 19$ \\
\hline
\end{tabular}

SPI/SG20, soya milk containing $20 \mathrm{mg}$ isoflavone/200 ml; SPI/SG40, soya milk containing $40 \mathrm{mg}$ isoflavone/200 ml; SPI/SG80, soya milk containing $80 \mathrm{mg}$ isoflavone/200 ml.

Means in the same row and column with different lower- and upper-case superscripts, respectively, are significantly different $(P<0.05)$.

* Mean total of daidzein, genistein and glycitein present after hydrolysis with $\beta$-glucuronidase/sulphatase (conjugated and unconjugated forms).

† Concentration of isoflavone in $24 \mathrm{~h}$ pooled urine specimen.

$\ddagger$ Consisting of two segregated groups consuming either the fermented or non-fermented soya milks.

$\S$ Eight $24 \mathrm{~h}$ pooled urine specimens (one per subject) analysed in duplicate.

I Total concentration of isoflavone isomers in $24 \mathrm{~h}$ pooled urine specimen collected $1 \mathrm{~d}$ before soya milk supplementation. 
according to the AUC of the appearance and disappearance concentrations in the plasma, which appeared to be due to the hydrolytic actions of intestinal $\beta$-glucosidases. To date, there is no evidence to indicate that ingesting isoflavones in an aglyconerich configuration enhances their bioavailability after either a single dose or consistent daily consumption.

Following the collection of a urine specimen at day 0 , we allowed $3 \mathrm{~d}$ of soya milk intake for women to reach a steady state of urinary isoflavone excretion and compared this with two $24 \mathrm{~h}$ pooled urine specimen collections at the completion of supplementation. There were no significant differences between the levels of total urinary isoflavone and the individual isomers (daidzein, genistein and glycitein) excreted on days 4, 13 and 14 of supplementation with fermented and non-fermented SPI/ SG20, SPI/SG40 and SPI/SG80 ( $P>0.05)$. Hence, a steady level of isoflavone absorption and urinary excretion appeared to have been achieved at each isoflavone dose for both fermented and non-fermented soya milk. Setchell et al. (2003) stated that optimum steady-state serum isoflavone concentrations would be expected from modest intakes of soya foods consumed regularly throughout the day rather than from a single, highly enriched product. Each subject in our study was required to consume the daily $200 \mathrm{ml}$ serving of soya milk as two portions, before breakfast and before dinner.

The positive correlation between the mean urinary excretion of total isoflavone per day versus the mean amount of total isoflavone ingested per day during supplementation with non-fermented and fermented soya milk is shown in Fig. 2(a) and 2(b), respectively. According to the computed lines of regression, there was a clearer linear relationship between isoflavone excretion and dose among fermented soya milks $\left(R^{2}=0.9993\right)$ compared with the linearity observed for non-fermented soya milks containing equivalent dosages of isoflavone $\left(R^{2}=0 \cdot 8865\right)$. Even though the consumption of fermented soya milk did not enhance urinary isoflavone excretion $(P>0.05)$ (Table 2$)$, it possibly reduced interindividual variability in isoflavone absorption and urinary excretion, indicated by the high linearity in dose response (Fig. 2(b)). This is reflected in Table 2, with values of standard deviation for urinary isoflavone excretion generally higher among the NFS group at each isoflavone dose.

The distinct linear dose response for the FS group (Fig. 2(b)) may have been due to the higher proportion of aglycone structures ingested via the fermented soya milks or the consumption of viable $B$. animalis $\mathrm{Bb}-12$. Turner et al. (2003) stated that the composition of intestinal microflora appears to play a key role in the intestinal biotransformation and absorption of isoflavones and may cause significant interindividual variability. Those women consuming the fermented soya milk may have established a more consistent intestinal microflora during supplementation by increasing the populations of $\beta$-glucosidase-producing bifidobacteria and adjusting intestinal microbial balance in favour of other saccharolytic enzyme-producing lactic acid bacteria. Hence, a greater variation in gut microflora between women consuming the non-fermented soya milks may have caused the poorer linearity in dose response (Fig. 2(a)). Furthermore, non-fermented soya milks probably contained a greater concentration of oligosaccharide compared with fermented soya milk; oligosaccharides are metabolised by $B$. animalis $\mathrm{Bb}-12$ during fermentation (Tsangalis $\&$ Shah, 2004). Soyabean oligosaccharides are classified as prebiotics, which stimulate the growth of bifidobacteria and other lactic acid-producing bacteria in the intestinal tract (Masai et al.
1987). This may have enhanced intestinal microbial metabolic activity in some subjects in the NFS group, potentially influencing the extent of isoflavone biotransformation and absorption. Not to be discounted are the deglycosylation of isoflavones by mammalian intestinal glucosidases (Day et al. 1998; Setchell et al. 2001) and the extent of their effect on interindividual variation in isoflavone absorption within the FS and NFS groups. Furthermore, Rowland et al. (2000) reported that the dietary intake of carbohydrate and fat also influenced the intestinal biotransformation of isoflavones. However, since both the FS and NFS groups had a similar daily intake of carbohydrate $(P=0 \cdot 7)$ and fat $(P=0.9)$, we believe that dietary intake had a lesser influence on interindividual variation in urinary isoflavone excretion within each group and the difference in linearity in isoflavone dose response shown in Fig. 2.

Bioavailability of daidzein, genistein and glycitein from fermented and non-fermented soya milk

The bioavailability of daidzein, genistein and glycitein appears to be dependent on the extent of their biotransformation in the intestinal tract. The deglycosylation of isoflavones by mammalian and microbial glucosidases results in the release of the aglycone form (Heinonen et al. 2002), which can undergo further structural changes. Joannou et al. (1995) reported that the reductive metabolism of daidzein results in the formation of equol and $O$-desmethylangolensin. Reductive metabolism transforms genistein
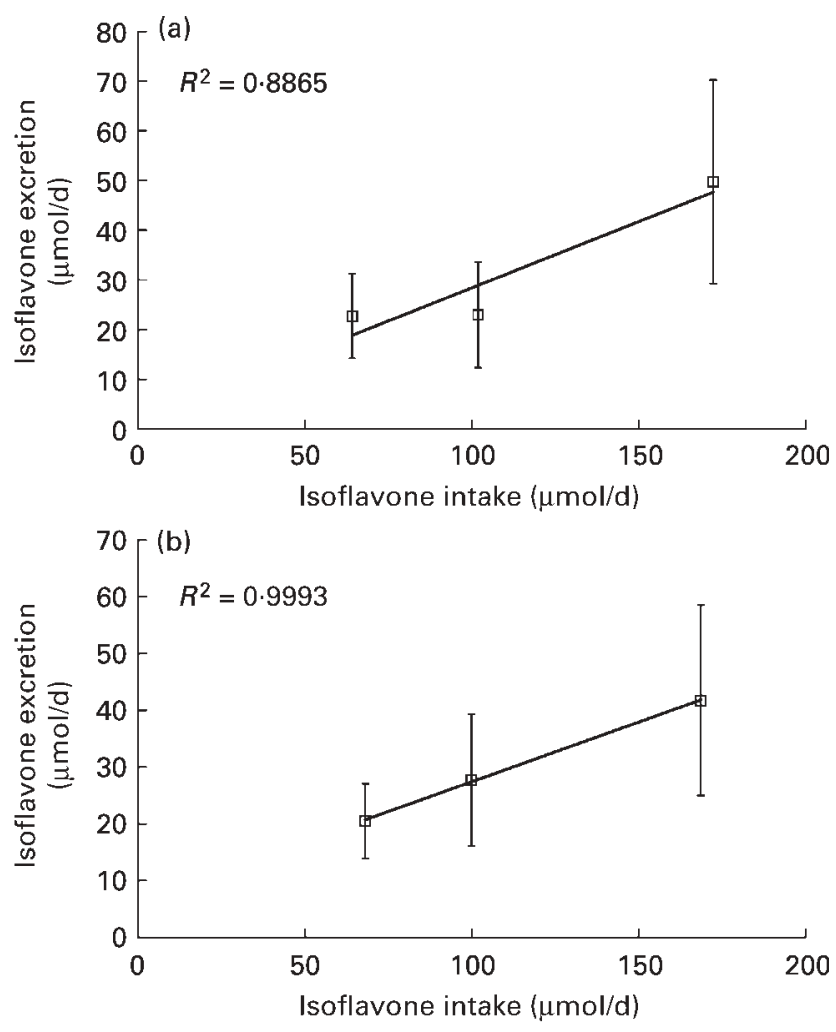

Fig. 2. Relationship between the urinary excretion of isoflavone (total of daidzein, genistein and glycitein) versus the amount of isoflavone ingested per day during supplementation with non-fermented (a) and fermented (b) soya milk. Data points and error bars represent the means and standard deviations of forty-eight replicates (eight subjects, three urine collection days and specimens analysed in duplicate). Solid lines represent the computed regression. 
into dihydrogenistein and 6'-OH-O-desmethylangolensin (Joannou et al. 1995). Recently, Heinonen et al. (2002) reported that glycitein also underwent reductive metabolism to form structures dihydroglycitein and the equol analogue of glycitein (6-OMe-equol). Consequently, pharmacokinetic studies have shown that there are differences in the extent of absorption and urinary excretion of daidzein, genistein and glycitein in human subjects, with large interindividual variability (Xu et al. 1994; King \& Bursill, 1998; Lu \& Anderson, 1998; Richelle et al. 2002).

The mean concentrations of daidzein, genistein and glycitein (total of conjugated and unconjugated forms) excreted in urine by the FS and NFS groups at 4, 13 and 14 d of soya milk supplementation are shown in Table 3 , and the percentage of ingested dose of daidzein, genistein and glycitein recovered in urine is shown in Fig. 3. On days 4, 13 and 14, the urinary excretion of daidzein was significantly greater than that of glycitein and genistein during supplementation with both fermented and non-fermented SPI/SG20, SPI/SG40 and SPI/SG80 $(P<0.001$; Table 3). Similarly, Richelle et al. (2002) reported that after the ingestion of an SG beverage, postmenopausal women excreted greater concentrations of daidzein in urine, followed by glycitein and genistein, with a urinary recovery of daidzein of approximately $53 \%$, compared with $34 \%$ and $19 \%$ for glycitein and genistein, respectively. Furthermore, Zhang et al. (2001) fed men and women (between the ages of 19 and 35 years) SG and found that the urinary recovery of daidzein was higher than that of glycitein $(P>0.05)$, although the recovery of daidzein and glycitein was significantly greater than that of genistein $(P<0 \cdot 05)$. Fig. 3 shows that the percentage recovery of daidzein in urine was significantly greater than that of both glycitein and genistein during supplementation with both fermented and non-fermented soya milk at all three isoflavone dosages $(P<0 \cdot 001)$. The percentage recovery of glycitein in urine was also greater than that of genistein during supplementation with fermented and non-fermented SPI/SG20, SPI/SG40 and SPI/SG80 ( $P>0 \cdot 05$; Fig. 3). Considering the profound differences in gut microflora between subjects from different countries and cultural backgrounds, as well as from different age groups (Mitsuoka, 1984), there appeared to be a consistent pattern in the urinary excretion and percentage recovery of isoflavone isomers found in our study and in the studies by Zhang et al. (2001) and Richelle et al. (2002). That is, the greatest of proportion of isoflavone in urine was found as daidzein, the smallest proportion as genistein, and the proportion as glycitein found somewhere in between.

According to the urinary isoflavone profiles shown in Table 3 and Fig. 3, the urinary recovery of genistein appears to be less than that of daidzein and glycitein. This is consistent with previous studies by Xu et al. (1994, 1995) and Lu et al. (1996), substantially reporting a higher urinary recovery of daidzein compared with genistein. Pharmacokinetic studies by King \& Bursill (1998) also found the urinary recovery of daidzein $(62 \%)$ to be significantly greater than that of genistein $(22 \%$; $P<0.001$ ). However, King \& Bursill (1998) concluded that the bioavailabilities of daidzein and genistein were similar considering that the ratio of the plasma AUC for genistein and daidzein was equal to the ratio of the concentration of the respective isoflavones in the soya meal ingested. Setchell et al. (2001) administered a $50 \mathrm{mg}$ dose of daidzein, daidzin, genistein or genistin to four groups of premenopausal women and found that the systemic bioavailability of genistein (mean AUC of $4.54 \mu \mathrm{g} / \mathrm{ml}$ per h) was much greater than that of daidzein (mean AUC of $2.94 \mu \mathrm{g} / \mathrm{ml}$ per h). Nevertheless, the results from previous urinary and plasma pharmacokinetic studies only involved the administration of a single dose. Over a period of daily soya isoflavone ingestion, the bioavailability of daidzein, genistein and glycitein may begin to differ depending on the response of intestinal microflora to the presence of these compounds. The lower concentrations of genistein in urine may be the result of its greater susceptibility to microbial breakdown in the intestinal tract. Xu et al. (1995) reported that genistein was more susceptible than daidzein to biotransformation by intestinal bacteria during anaerobic incubations of human faecal samples. However, as we did not measure concentrations of these isoflavones in timed plasma samples, we cannot assume a reduced bioavailability of genistein based on percentage urinary recovery alone. Genistein may have been absorbed more extensively than suggested by its urinary recovery but may have undergone greater metabolism and/or excretion by non-renal mechanisms.

Women consuming both the fermented and non-fermented SPI/ SG80 excreted significantly greater levels of daidzein (ranging from 28 to $37 \mu \mathrm{mol} / \mathrm{d}$ ) on days 4,13 and 14 of supplementation, compared with the consumption of SPI/SG20 and SPI/SG40 (Table 3). The greater level of daidzein and its glucosidic conjugates in SPI/SG80 (Table 1) appeared to account for the increased absolute absorption and urinary excretion of this isomer in the FS and NFS groups. However, the percentage recovery of daidzein in urine tended to be greater for women consuming fermented and non-fermented SPI/SG20 (57\% and $63 \%$ of dose, respectively; $P>0.05$ ) (Fig. 3). Concentrations of daidzein and its glucosides at approximately $22.6 \mu \mathrm{mol}(5.7 \mathrm{mg})$ aglycone constituents per $200 \mathrm{ml}$, found in SPI/SG20, appear to be less susceptible to microbial breakdown (reductive metabolism) in the gastrointestinal tract and more bioavailable according to percentage recovery of dose. Lower doses of daidzein may be absorbed more effectively in the proximal gastrointestinal tract, reflecting more complete absorption. With higher doses of daidzein, the fraction not absorbed proximally may be absorbed distally in the gastrointestinal tract, where there are greater populations of intestinal bacteria possibly biotransforming daidzein into equol, dihydrodaidzein and other metabolites prior to absorption, accounting for the lower percentage recovery of dose for SPI/ SG40 and SPI/SG80 (Fig. 3). There was a trend towards an increased excretion and urinary recovery of equol during supplementation with SPI/SG80 $(P>0.05)$, especially in the FS group (results not shown). Limited or saturable absorption of daidzein in the proximal gastrointestinal tract may be the reason why higher ingested doses of daidzein pass into the ileum and colon. This may be influenced by the efficacy of mammalian glucosidases present in the proximal intestinal tract to hydrolyse glucosidic isomers of daidzein into a bioavailable aglycone configuration, as there are considerably lower populations of bacteria in this region compared with the ileum and colon (Turner et al. 2003).

In contrast to the urinary excretion of daidzein, Table 3 shows that there were no significant differences in the urinary excretion of genistein during supplementation with fermented and non-fermented SPI/SG20, SPI/SG40 and SPI/SG80 at day 4, 13 and 14 $(P>0.05)$. In this case, increasing the dose of genistein was not associated with increased urinary excretion of this isomer, due possibly to its greater susceptibility to intestinal microbial breakdown in comparison to daidzein (Xu et al. 1995); alternatively, this could reflect a limited or saturable absorptive capacity in 
Table 3. Urinary excretion of total ${ }^{*}$ daidzein, genistein and glycitein ( $\left.\mu \mathrm{mol} / \mathrm{d} \dagger\right)$ by two groups of eight women $\ddagger$ during supplementation of fermented and non-fermented soya milks SPI/SG20, SPI/SG40 and SPI/SG80

(Mean values with their standard deviations; $n 16 \S$ )

\begin{tabular}{|c|c|c|c|c|c|c|c|c|c|c|c|c|}
\hline \multirow{3}{*}{$\begin{array}{l}\text { Isoflavone } \\
\text { isomer Day } \\
\text { of } 24 \mathrm{~h} \text { urine } \\
\text { collection }\end{array}$} & \multicolumn{6}{|c|}{ Non-fermented } & \multicolumn{6}{|c|}{ Fermented } \\
\hline & \multicolumn{2}{|c|}{ SPI/SG20 } & \multicolumn{2}{|c|}{ SPI/SG40 } & \multicolumn{2}{|c|}{ SPI/SG80 } & \multicolumn{2}{|c|}{ SPI/SG20 } & \multicolumn{2}{|c|}{ SPI/SG40 } & \multicolumn{2}{|c|}{ SPI/SG80 } \\
\hline & Mean & SD & Mean & SD & Mean & SD & Mean & SD & Mean & SD & Mean & SD \\
\hline \multicolumn{13}{|l|}{ Daidzein } \\
\hline Baseline & $0.23^{a}$ & 0.37 & $0.26^{\mathrm{a}}$ & 0.23 & $0 \cdot 16^{\mathrm{a}}$ & 0.25 & $0 \cdot 11^{a}$ & 0.14 & $0.29^{\mathrm{a}}$ & 0.39 & $0.27^{\mathrm{a}}$ & 0.37 \\
\hline Day 4 & $15 \cdot 00^{\text {cde, } A}$ & $5 \cdot 41$ & $11.44^{\mathrm{e}, \mathrm{A}}$ & $7 \cdot 72$ & $35.87^{\mathrm{a}, \mathrm{A}}$ & $6 \cdot 35$ & $12 \cdot 33^{\mathrm{de}, \mathrm{A}}$ & $6 \cdot 28$ & $15 \cdot 09^{\text {bcde, } A}$ & $5 \cdot 74$ & $27 \cdot 49^{\mathrm{a}, \mathrm{A}}$ & 15.95 \\
\hline Day 14 & $11.93^{\mathrm{e}, \mathrm{A}}$ & 5.85 & $15 \cdot 01^{\mathrm{cde}, \mathrm{A}}$ & $8 \cdot 16$ & $37.07^{\mathrm{a}, \mathrm{A}}$ & $19 \cdot 31$ & $13.06^{\mathrm{de}, \mathrm{A}}$ & 4.04 & $18.54^{\text {bcde, } A}$ & $7 \cdot 80$ & $32.56^{\mathrm{a}, \mathrm{A}}$ & 13.23 \\
\hline \multicolumn{13}{|l|}{ Genistein } \\
\hline Baseline & $0 \cdot 17^{\mathrm{a}}$ & 0.22 & $0 \cdot 13^{a}$ & 0.16 & $0.04^{\mathrm{a}}$ & 0.04 & $0.05^{\mathrm{a}}$ & 0.13 & $0.19^{a}$ & 0.32 & $0.09^{a}$ & 0.08 \\
\hline Day 4 & $5 \cdot 01^{\mathrm{a}, \mathrm{A}}$ & 1.60 & $4.49^{\mathrm{a}, \mathrm{A}}$ & 3.64 & $5 \cdot 02^{a, A}$ & 1.66 & $6 \cdot 06^{\mathrm{a}, \mathrm{A}}$ & 3.45 & $5 \cdot 23^{\mathrm{a}, \mathrm{A}}$ & 2.94 & $5 \cdot 35^{\mathrm{a}, \mathrm{A}}$ & $4 \cdot 27$ \\
\hline Day 13 & $4.95^{\mathrm{a}, \mathrm{A}}$ & 2.45 & $6 \cdot 68^{\mathrm{a}, \mathrm{A}}$ & 5.97 & $5 \cdot 28^{a, A}$ & 2.63 & $3.96^{\mathrm{a}, \mathrm{A}}$ & 1.97 & $6 \cdot 07^{\mathrm{a}, \mathrm{A}}$ & 3.48 & $5 \cdot 32^{\mathrm{a}, \mathrm{A}}$ & 1.88 \\
\hline Day 14 & $5 \cdot 26^{\mathrm{a}, \mathrm{A}}$ & 3.05 & $4 \cdot 90^{\mathrm{a}, \mathrm{A}}$ & 4.00 & $6 \cdot 18^{\mathrm{a}, \mathrm{A}}$ & $4 \cdot 72$ & $5 \cdot 94^{\mathrm{a}, \mathrm{A}}$ & 2.48 & $5 \cdot 77^{\mathrm{a}, \mathrm{A}}$ & $2 \cdot 82$ & $5 \cdot 36^{\mathrm{a}, \mathrm{A}}$ & 3.75 \\
\hline \multicolumn{13}{|l|}{ Glycitein } \\
\hline Baseline & ND & & ND & & ND & & ND & & ND & & ND & \\
\hline Day 4 & $4 \cdot 29^{\mathrm{d}, \mathrm{A}}$ & 1.55 & $5 \cdot 26^{\mathrm{bcd}, \mathrm{A}}$ & 3.48 & $10 \cdot 12^{\mathrm{a}, \mathrm{A}}$ & 5.51 & $4 \cdot 31^{\mathrm{cd}, \mathrm{A}}$ & 1.68 & $5 \cdot 90^{\mathrm{abcd}, \mathrm{A}}$ & $4 \cdot 15$ & $7 \cdot 11^{\mathrm{abcd}, \mathrm{A}}$ & 4.21 \\
\hline Day 14 & $3 \cdot 65^{\mathrm{cd}, \mathrm{A}}$ & $2 \cdot 87$ & $4.43^{\mathrm{bcd}, \mathrm{A}}$ & 3.31 & $10 \cdot 38^{a, A}$ & 6.49 & $3.52^{\mathrm{d}, \mathrm{AB}}$ & 1.88 & $5.47^{\mathrm{abcd}, \mathrm{A}}$ & $3 \cdot 12$ & $7 \cdot 88^{\mathrm{abcd}, \mathrm{A}}$ & 5.08 \\
\hline
\end{tabular}

SPI/SG20, soya milk containing $20 \mathrm{mg}$ isoflavone $/ 200 \mathrm{ml}$; SPI/SG40, soya milk containing $40 \mathrm{mg}$ isoflavone/200 ml; SPI/SG80, soya milk containing $80 \mathrm{mg}$ isoflavone/200 ml; $\mathrm{ND}$, not detected in $20 \mathrm{ml}$ urine specimen using an injection volume of $50 \mu \mathrm{l}$.

Means in the same row (arranged as six values across) and column (arranged as three values down) with different lower- and upper-case superscripts, respectively, are significantly different $(P<0.05)$.

${ }^{*}$ Concentration of daidzein, genistein and glycitein after $\beta$-glucuronidase/sulphatase deconjugation (conjugated and unconjugated forms).

† Concentration of daidzein, genistein and glycitein in $24 \mathrm{~h}$ pooled urine specimen.

$\ddagger$ Consisting of two segregated groups consuming either the fermented or non-fermented soya milks

$\S$ Eight $24 \mathrm{~h}$ pooled urine specimens (one per subject) analysed in duplicate.

1. Concentration of daidzein, genistein and glycitein in $24 \mathrm{~h}$ pooled urine specimen collected $1 \mathrm{~d}$ before soya milk supplementation.

the gastrointestinal tract. However, it can be seen in Table 1 that the difference in dosage levels of genistein and its glucosides from each of the fermented and non-fermented forms of SPI/ SG20, SPI/SG40 and SPI/SG80 were not as distinctly different as those of daidzein between these soya milks. Furthermore, comparable genistein dosage levels between soya milks may have

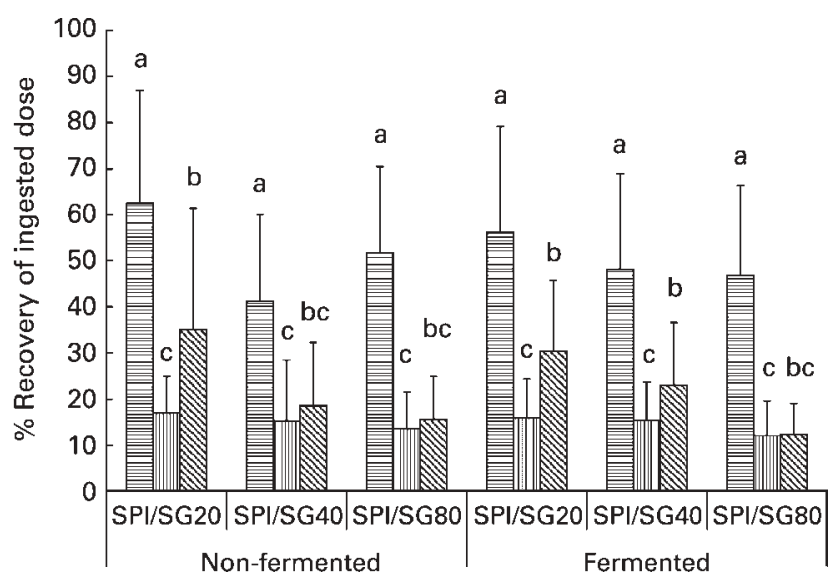

Fig. 3. Ratio of the amount of daidzein 目, genistein $\mathbb{U}$ and glycitein $\mathbb{\mathbb { Q }}$ (total of conjugated and unconjugated forms) recovered in urine to the intake of each isomer per day (expressed as a percentage) from non-fermented and fermented soya milk. Columns and errors bars represents 3 mean and standard deviations of forty-eight replicates (eight subjects, three urine collection days and specimens analysed in duplicate). Means of daidzein, genistein and glycitein arranged as three columns were analysed using one-way ANOVA. Columns with different letters are significantly different $(P<0.05)$. SPI/SG20: soya milk containing $20 \mathrm{mg}$ isoflavone/ $200 \mathrm{ml}$; SPI/SG40: soya milk containing $40 \mathrm{mg}$ isoflavone/200 ml; SPI/SG80: soya milk containing $80 \mathrm{mg}$ isoflavone/ $200 \mathrm{ml}$. caused the similar percentage recovery of genistein in urine between fermented and non-fermented SPI/SG20, SPI/SG40 and SPI/SG80, in the range of $14-17 \%$ of ingested dose $(P>0.05$; Fig. 3). In comparison, Hutchins et al. (1995) reported that the mean urinary recovery of genistein among a group of men consuming fermented soyabean pieces (tempeh) was only $1.9 \%$ at a dosage of $44.5 \mu \mathrm{mol}$ genistein d, equivalent to the dosage of fermented SPI/SG80 $(44.4 \mu \mathrm{mol}$ genistein/d). The mean urinary recovery of daidzein from the same group was $9.7 \%$ at a dosage of $21.3 \mu \mathrm{mol}$ daidzein d (Hutchins et al. 1995), considerably lower than the mean urinary recovery of daidzein among the FS group (57\% of ingested dose) ingesting an equivalent dosage of daidzein via SPI/SG20 (23.3 $\mu \mathrm{mol}$ daidzein/d). The greater percentage recovery of daidzein and genistein in our study may have been due to the greater proportion of unconjugated daidzein in fermented SPI/SG20 (73\% of dose) and unconjugated genistein in fermented SPI/SG80 (53\% of dose). According to Hutchins et al. (1995), tempeh comprised $22 \%$ and $10 \%$ of its total daidzein and genistein concentration, respectively in an unconjugated form. Alternatively, soya milk has a greater proportion of simple isoflavone glucosides ( $\beta$-glucoside isomers) than do less processed soya foods, which are possibly easier to hydrolyse into bioavailable aglycones via mammalian and microbial glucosidases (King \& Bursill, 1998).

Even though the urinary excretion of glycitein resembled a linear response to dose in the FS group, there were no significant differences at day 4,13 or 14 to suggest that increasing the dosage level of glycitein significantly enhanced the absorption and urinary excretion of this isomer (Table 3 ). As with the urinary recovery of daidzein, a significantly greater percentage recovery (in the range of 30-35\%) was observed when ingesting the lowest level of glycitein via fermented and non-fermented SPI/SG20 
$(P<0.001$; Fig. 3), comprising a glycitein concentration of approximately $12.0 \mu \mathrm{mol}(3.4 \mathrm{mg})$ aglycone constituents per $200 \mathrm{ml}$ serving. Fig. 3 also shows that women consuming fermented SPI/SG40 tended to have a greater percentage recovery of glycitein ( $22 \%$ of dose) in comparison to the ingestion of non-fermented SPI/SG40 (urinary recovery of $18 \% ; P=0 \cdot 13$ ). Similarly, the percentage recovery of daidzein in urine also tended to be greater among women consuming fermented SPI/ SG40 (48\% of dose) compared with women consuming non-fermented SPI/SG40 (urinary recovery of $41 \% ; P=0 \cdot 14$ ).

In an earlier crossover study, Hutchins et al. (1995) assigned an adequate $12 \mathrm{~d}$ washout period between each of their $9 \mathrm{~d}$ feeding periods. Since our study involved daily soya milk ingestion for up to $14 \mathrm{~d}$, we decided to implement a similar time period to our washout phase as used by Hutchins et al. (1995). Previous pharmacokinetic studies involving a single serving of soya food generally used shorter washout periods of 5-6 d (King \& Bursill, 1998; Richelle et al. 2002), which we believed may not have been adequate considering the longer exposure to isoflavones and the potential for enterohepatic recirculation. Nevertheless, urinary isoflavones were detected on day 0 (baseline) of each of the isoflavone dosages ingested (Table 2), suggesting that the $14 \mathrm{~d}$ washout period implemented in the crossover design was not long enough to fully excrete circulating isoflavone metabolites in each of the women. Alternatively, isoflavones detected in baseline urine specimens may have been the result of women unknowingly ingesting foods or ingredients containing isoflavones, which were supposed to be excluded during the supplementation and washout periods. This might have been clarified had the subjects recorded their dietary intake during the washout periods in order to assess whether the presence of isoflavones at baseline was the result of physiological or dietary reasons. Of the individual isomers, low concentrations of both daidzein and genistein were detected at baseline for both the FS and NFS groups (Table 3). In contrast, glycitein was not detected in baseline urine specimens (Table 3), $14 \mathrm{~d}$ appearing to be an adequate period to wash out glycitein from the circulatory system. Then again, if dietary intake during the washout phases was the reason for the presence of isoflavones in the baseline urine specimens, glycitein may not have been detected because it is found at considerably lower levels than daidzein and genistein in conventional soya foods and ingredients found in Australia (King \& Bignell, 2000).

From a health perspective, isoflavones may be of greater benefit to those women who are able to retain biologically active isoflavone metabolites in their circulatory system for longer periods of time after discontinuing the intake of soya foods. In the NFS group, the woman who excreted the greatest level of isoflavone after two $14 \mathrm{~d}$ washout periods also had the highest BMI, at approximately $39 \mathrm{~kg} / \mathrm{m}^{2}$. Isoflavones in an aglycone form are lipid soluble; hence, women with a higher percentage of body fat may have a greater tendency to retain isoflavones.

\section{Conclusions}

The fermentation of each soya milk with $B$. animalis Bb-12 enriched the level of bioavailable isoflavone aglycone. Additionally, each soya milk was able to support the viability of $B$. animalis Bb-12 during refrigerated storage at levels able effectively to modulate intestinal microbial balance. There was, however, no strong evidence to suggest that fermenting soya milk with bifidobacteria improved the bioavailability of isoflavone in postmenopausal women over $14 \mathrm{~d}$ of daily soya milk ingestion. Levels of total isoflavone (unconjugated and conjugated forms) excreted in urine and urinary isoflavone recovery was similar for both groups of women consuming either fermented or non-fermented soya milks. Nevertheless, the ingestion of fermented soya milk appeared to reduce the interindividual variation in isoflavone absorption. Of the individual isomers, the percentage recovery of daidzein and glycitein in urine tended to be greater among women consuming fermented soya milk at a daily dosage of $40 \mathrm{mg}$ isoflavone. Increasing the dosage of isoflavone correlated positively with the urinary excretion of isoflavone, but the urinary recovery of isoflavone was inversely related to dosage level. Hence, a modest isoflavone dosage ranging from 20 to $30 \mathrm{mg}$ aglycone constituents per day may provide the most bioavailable source of isoflavone. Finally, according to the isoflavone profiles excreted in urine, there is no preliminary evidence to indicate that ingesting soya milk fermented with bifidobacteria will enhance the potential health benefit of isoflavone compared with an equivalent non-fermented soya milk. Studies investigating the physiological effects of the concomitant ingestion of isoflavone and probiotic bifidobacteria on biomarkers of disease risk in postmenopausal women are currently underway.

\section{Acknowledgements}

The Australian Research Council's Strategic Partnership with Industry (Sanitarium Health Food Company) for Research and Training scheme funded this research. We gratefully acknowledge the assistance given by Professor Paul Komesaroff (Alfred Hospital, Melbourne, Victoria, Australia) when preparing the ethics application and documentation for subjects. We also would like to thank Dr John Ashton of Sanitarium Health Food Company for his support and for providing the soya germ powder required for soya milk manufacture.

\section{References}

Albright SC, Winston WL \& Zappe C (1999) Data Analysis and Decision Making with Microsoft Excel. Pacific Grove, CA: Brooks/Cole Publishing Company.

Anderson JW, Johnstone BM \& Cook-Newell ME (1995) Meta-analysis of the effects of soy protein intake on serum lipids. $N$ Eng $J$ Med 333, 276-282.

Ballongue J (1993) Bifidobacteria and probiotic action. In Lactic Acid Bacteria, pp. 519-587 [S Salminen and A von Wright, editors]. New York: Marcel Dekker.

Brzezinski A \& Debi A (1999) Phytoestrogens: the "natural" selective estrogen receptor modulators? Eur J Obstet Gynaecol 85, 47-51.

Cassidy A (1996) Physiological effects of phyto-oestrogens in relation to cancer and other human health risks. Proc Nutr Soc 55, 399-417.

Day AJ, DuPont MS, Ridley S, Rhodes M, Rhodes MJ, Morgan MR \& Williamson G (1998) Deglycosylation of flavonoid and isoflavonoid glycosides by human small intestine and liver beta-glucosidase activity. FEBS Lett 436, 71-75.

De Mann JC, Rogosa M \& Sharpe ME (1960) A medium for the cultivation of lactobacilli. J Appl Bacteriol 23, 130-135.

Franke AA \& Custer LJ (1994) High-performance liquid chromatography assay of isoflavonoids and coumesterol from human urine. J Chromatog $B$ 662, 47-60.

Gomes AMP \& Malcata FX (1999) Bifidobacterium spp. and 
Lactobacillus acidophilus: biological, biochemical, technological and therapeutical properties relevant for use as probiotics. Trends Food Sci Technol 10, 139-157.

Heinonen SM, Wähälä K \& Adlercreutz H (2002) Metabolism of isoflavones in human subjects. Phytochem Rev 1, 175-182.

Hendrich S (2002) Bioavailability of isoflavones. J Chromatog B 777, 203-210.

Hendrich S, Hu J, Zheng YL, Lee SO, Verbruggen M \& Murphy PA (2001) Comparative bioavailability of isoflavone aglycone and glucosides in women. Fourth International Symposium on the Role of Soy in Preventing and Treating Chronic Disease. San Diego, CA, November 4-7.

Hou JW, Yu RC \& Chou CC (2000) Changes in some components of soya milk during fermentation with bifidobacteria. Food Res Int 33, 393-397.

Hutchins AM, Slavin JL \& Lampe JW (1995) Urinary isoflavonoid phytoestrogen and lignan excretion after consumption of fermented and unfermented soy products. J Amer Diet Assoc 95, 545-551.

Izumi T, Piskula MK, Osawa S, Obata A, Tobe K, Saito M,Kataoka S, Kubota Y \& Kikuchi M (2000) Soy isoflavone aglycones are absorbed faster and in higher amounts than their glucosides in humans. $J$ Nutr 130, $1695-1699$.

Joannou GE, Kelly GE, Reeder AY, Waring M \& Nelson C (1995) A urinary profile study of dietary phytoestrogens. The identification and mode of metabolism of new isoflavonoids. J Steroid Biochem Mol Biol 54, $167-185$.

Kamaly KM (1997) Bifidobacteria fermentation of soybean milk. Food Res Int 30, 675-682.

Kelly GE, Nelson C, Waring MA, Joannou GE \& Reeder AY (1993) Metabolites of dietary (soya) isoflavones in human urine. Clin Chim Acta 223, 9-22.

King RA \& Bignell CM (2000) Concentrations of isoflavone phytoestrogens and their glucosides in Australian soya beans and soya foods. Aus J Nutr Diet 57, 70-78.

King RA \& Bursill DB (1998) Plasma and urinary kinetics of the isoflavones daidzein and genistein after a single soy meal in humans. Am J Clin Nutr 67, 867-872.

Kudou S, Fleury Y \& Welti D (1991) Malonyl isoflavone glycosides in soybean seeds (Glycine Max merrill). Agric Biol Chem 55, 2227-2233.

Kurzer MS (2000) Hormonal effects of soy isoflavones: studies in premenopausal and postmenopausal women. J Nutr 130, 660S-661S.

Lampe JW, Karr SC, Hutchins AM \& Slavin JL (1998) Urinary equol excretion with a soy challenge: influence of habitual diet. Proc Soc Exp Biol Med 217, 335-339.

Lee HP, Gourley L, Duffy SW, Esteve J, Lee J \& Day NE (1991) Dietary effects on breast cancer risk in Singapore. Lancet 337, 1197-1200.

Lu L-JW \& Anderson KE (1998) Sex and long-term soy diets affect the metabolism and excretion of soy isoflavones in humans. Am J Clin Nutr 68, 1500S-1504S.

Lu L-JW, Lin SN, Grady JJ, Nagamani M \& Anderson KE (1996) Altered kinetics and extent of urinary daidzein and genistein excretion in women during chronic soya exposure. Nutr Cancer 26, 289-302.

Markiewicz L, Garey J, Adlercreutz H, Gurpide E (1993) In vitro bioassays of non-steroidal phytoesrogens. J Steroid Biochem Mol Biol 45, 399-405.

Masai T, Wada K, Hayakawa K, Yoshihara I \& Mitsuoka T (1987) Effects of soybean oligosaccharides on human intestinal flora and metabolic activities. Japan J Bacteriol 42, 313.

Mayr U, Butsch A \& Schneider S (1992) Validation of two in vitro test systems for estrogenic activities with zearalenone, phytoestrogens and cereal extracts. Toxicology 74, 135-149.

Mitsuoka T (1984) Taxonomy and ecology of bifidobacteria. Bifidobacteria Microflora 1, 11-28.

Murphy PA, Song T, Buseman G, Barua K, Beecher GR, Trainer D \& Holden V (1999) Isoflavones in retail and institutional soy foods. $J$ Agric Food Chem 47, 2697-2704.
Orrhage K \& Nord CE (2000) Bifidobacteria and lactobacilli in human health. Drugs Exp Clin Res 26, 95-111.

Playne MJ (2002) The health benefits of probiotics. Food Aust 54, 71-74.

Richelle M, Pridmore-Merten S, Bodenstab S, Enslen M \& Offord EA (2002) Hydrolysis of isoflavone glycosides to aglycones by $\beta$-glycosidase does not alter plasma and urine isoflavone pharmacokinetics in postmenopausal women. J Nutr 132, 2587-2592.

Rowland IR, Wiseman H, Sanders TAB, Adlercreutz H \& Bowey EA (2000) Interindividual variation in metabolism of soy isoflavones and lignans: influence of habitual diet on equol production by the gut microflora. Nutr Cancer 36, 27-32.

Setchell KDR (1995) Non-steroidal estrogens of dietary origin: possible roles in health and disease, metabolism and physiological effects. Proc Nutr Soc NZ 20, 1-21.

Setchell KDR \& Cassidy A (1999) Dietary isoflavones: biological effects and relevance to human health. J Nutr 129, 758S-767S.

Setchell KDR, Borriello SP, Hulme P, Kirk DN \& Axelson M (1984) Nonsteroidal estrogens of dietary origin: possible roles in hormone-dependent disease. Am J Clin Nutr 40, 569-578.

Setchell KDR, Brown NM, Desai P, Zimmer-Nechemias L, Wolfe BE, Brashear WT, kirschner AS, Cassidy A \& Heubi VE (2001) Bioavailability of pure isoflavones in healthy humans and analysis of commercial soy isoflavone supplements. $J$ Nutr 131, 1362S-1375S.

Setchell KDR, Brown NM, Zimmer-Nechemias L, Brasheas WT, Wolfe BE, Krischner AS \& Heubi JE (2002) Evidence for the lack of absorption of soy isoflavone glycosides in humans, supporting the crucial role of intestinal metabolism for bioavailability. Amer J Clin Nutr 76, $447-453$.

Setchell KDR, Maynard-Brown N, Desai PB, Zimmer-Nechemias L, Wolfe B, Jakate AS, Creutzinger V \& Heubi VE (2003) Bioavailability, disposition, and dose-response effects of soy isoflavones when consumed by healthy women at physiologically typical dietary intakes. J Nutr 133, 1027-1035.

Slavin JL, Karr SC, Hutchins AM \& Lampe JW (1998) Influence of soybean processing, habitual diet, and soy dose on urinary isoflavonoid excretion. Amer J Clin Nutr 68, 1492S-1495S.

Tsangalis D \& Shah NP (2004) Metabolism of oligosaccharides and aldehydes and production of organic acids in soya milk by probiotic bifidobacteria. Int J Food Sci Technol 39, 541-554.

Tsangalis D, Ashton JF, McGill AEJ \& Shah NP (2002) Enzymic transformation of isoflavone phytoestrogens in soya milk by $\beta$-glucosidase-producing bifidobacteria. J Food Sci 67, 3104-3113.

Tsangalis D, Ashton JF, McGill AEJ \& Shah NP (2003) Biotransformation of isoflavones by bifidobacteria in fermented soya milk supplemented with D-glucose and L-cysteine. J Food Sci 68, 623-631.

Tsangalis D, Ashton JF, Stojanovska L, Wilcox G \& Shah NP (2004) Development of an isoflavone aglycone enriched soya milk using soy germ, soy protein isolate and bifidobacteria. Food Res Int 37, 301-312.

Turner NJ, Thomson BM \& Shaw IC (2003) Bioactive isoflavones in functional foods: the importance of gut microflora on bioavailability. Nutr Rev 61, 204-213.

Xu X, Harris KS, Wang H-J, Murphy PA \& Hendrich S (1995) Bioavailability of soybean isoflavones depends upon gut microflora in women. $J$ Nutr 125, 2307-2315.

Xu X, Wang H-J, Murphy PA, Cook L \& Hendrich S (1994) Daidzein is a more bioavailable soya milk isoflavone than is genistein in adult women. $J$ Nutr 124, 825-832.

Zhang Y, Hendrich S \& Murphy PA (2003) Glucuronides are the main isoflavone metabolites in women. J Nutr 133, 399-404.

Zhang Y, Wang G-J, Song TT, Murphy PA \& Hendrich S (2001) Urinary disposition of the soybean isoflavones daidzein, genistein and glycitein among humans with moderate fecal isoflavone degradation activity (erratum). J Nutr 131, 147-148. 